\title{
Editorial
}

Interational Archives of
Allergy
Immunology

Published online: January 25, 2014

DOI: $\underline{10.1159 / 000357946}$

\section{Bugs versus Bugs: Probiotics, Microbiome and Allergy}

\section{Cecilia Berin}

Pediatric Allergy and Immunology, Immunology Institute and Tisch Cancer Institute, Icahn School of Medicine at Mount Sinai, New York, N.Y., USA

Probiotics, defined as 'live organisms which, when administered in adequate amounts, confer a health benefit to the host' [1] have a long history of human use, such as the ingestion of fermented milk products for health purposes. Commonly used probiotics include Lactobacillus or Bifidobacterium species, which have effects on the immune system and intestinal barrier function that support their use in the prevention or treatment of immune-mediated disorders [2-4]. It remains poorly understood, however, how probiotics actually interact with our commensal bacteria. The intestine, particularly the large intestine, is heavily colonized and commensal bacteria outnumber human cells by a factor of 10 to 1 . The intestinal microbiota plays a key role in the maintenance of mucosal health: it helps to metabolize nutrients, produce shortchain fatty acids required for epithelial metabolism and has broad-ranging effects on the mucosal barrier, immune function and metabolism [5]. Manipulation of health by altering the microbiome was first systematically applied to livestock, where both antibiotics and probiotics have been used to promote weight gain [6].

\section{Microbiome and Allergy}

The growing prevalence of atopic disease in the developed world led to the proposition of the hygiene hypothesis by Strachan [7] in 1989, in which he posited that the rise in atopic disease was due to a decreased childhood exposure to infections. Although exposure to infections may be one source of immune education, the most extensive interaction of the human body with microbes occurs within our own gut, which, in addition to being the site of greatest bacterial colonization, is also the largest lymphoid organ in the body. Over 40 years ago, it was reported that germ-free status resulted in spontaneous allergy and anaphylaxis to dietary milk in rabbits [8], suggesting that the microbiota is important for actively suppressing allergic sensitization and supporting the concept of 'good bugs' that could be used therapeutically. It has been proposed that a change in the constituents of the intestinal microbiota promotes allergic disease, a concept supported by recent preclinical data [9]. Using culture-based approaches to studying the human microbiome, there has been a lack of consistent findings comparing healthy to atopic infants $[10,11]$. However, the vast majority of commensal bacteria cannot be cultured and are not represented in such approaches. The development of highthroughput genomic approaches for quantifying taxonomic units has been used to study stool samples from atopic infants compared to healthy controls, with a finding of reduced diversity and dysbiosis in allergic disease $[12,13]$. Readers are referred to Garn et al. [14] for a comprehensive review of the current state of microbiome research in allergic disease. Studies on larger birth cohorts are needed to definitively answer the question of how changes in the microbiome precede the development of atopic disease. Advances in sequencing techniques now

\section{KARGER}

E-Mail karger@karger.com

www.karger.com/iaa (c) 2014 S. Karger AG, Basel

$1018-2438 / 14 / 1633-0165 \$ 39.50 / 0$
Correspondence to: Dr. M. Cecilia Berin

Icahn School of Medicine at Mount Sinai

1470 Madison Ave, 5-119

New York, NY 10029 (USA)

E-Mail cecilia.berin@mssm.edu 
Fig. 1. It is not yet known how the microbiota is altered in those with allergic disease beyond a reduction in diversity. More research is needed in order to identify, at the species level, what prevents or promotes allergic disease and to determine how the balance is altered in allergy. Furthermore, an understanding of how probiotic treatment influences microbial colonization is currently missing from probiotics research; this could shed light on how probiotics could be most effectively used for the prevention or treatment of allergy.

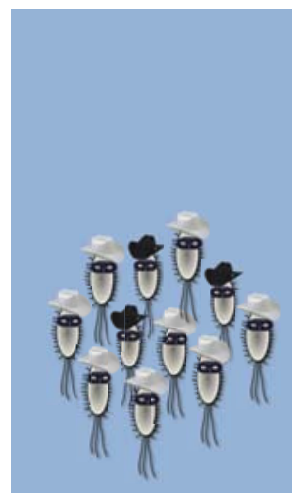

Healthy microbiota

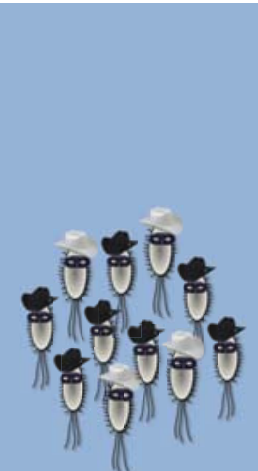

Allergic microbiota

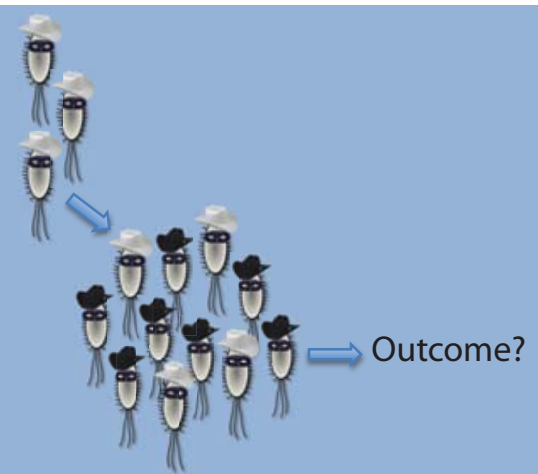

+ Probiotics allow for accurate identification to the species level over time [15], which will allow for the determination of whether there are species that prevent or promote the development of allergic disease. This 'good bug/bad bug' concept is fundamental to the theory of probiotic treatment (fig. 1).

\section{Probiotics and Allergic Disease}

Probiotics tested in human trials for the prevention of allergic disease include Lactobacillus or Bifidobacterium species or probiotic cocktails, given either postnatally or prenatally and postnatally. Preclinical studies on mice have supported an immunomodulatory effect of these microbes, either in suppressing Th2 responses or promoting Th1 or Treg responses. Human trials have been associated with variable outcomes in the prevention of eczema and allergic sensitization. In this issue of International Archives of Allergy and Immunology, Loo et al. [16] provide 5-year follow-up data on a cohort of 253 Asian infants at a high risk of allergic disease. Infants were randomized to receive a commercially available milk formula supplemented with Bifidobacterium longum and Lactobacillus rhamnosus, or not supplemented, for the first 6 months of life. In a previous report, after following these infants up to the age of 12 months, the investigators reported that there was no significant effect of probiotic treatment on outcomes of eczema or allergic sensitization [17]. In their current report, based on follow-up of the cohort yearly up to the age of 5 years, they found that there was no significant effect of early probiotic use on eczema, asthma, allergic rhinitis, food allergy or sensitization to dust-mite allergens. An interesting aspect of the report was that $92 \%$ of subjects used probiotics for a period of at least 1 year after the age of 2 years, making the group that had no regular exposure to probiotics up to the 5 th year of life very small. This postintervention probiotic use was significantly associated with a reduced incidence of asthma and allergic rhinitis. These data suggest that prolonged use of probiotics may contribute to their effectiveness.

A recent meta-analysis [18] reported a significant effect of probiotic use on total IgE and allergic sensitization, but no effect on asthma or wheeze. However, this was a finding only in studies that started supplementation prenatally. Since the infant microbiome is derived primarily from the mother, it may be necessary to alter the maternal microbiome in order to secure significant changes in the infant microbiome. Alternatively, alterations in the maternal microbiome could potentially alter factors in breast milk that could promote immune tolerance. However, in the absence of information on how probiotic treatment influences either the maternal or the infant microbiome, the mechanism of action remains speculative.

\section{Future Directions in Probiotic Research}

The concept of the prevention of allergic disease through manipulation of the gut microbiota is highly appealing. As emphasized in a recent position paper from the World Allergy Organization [19], research on probiotics is still in its infancy and there is more work that 
needs to be done to evaluate potential efficacy. Future studies need to consider the impact of probiotic treatment on the microbiome (both maternal and infant). There are data that feeding Lactobacillus casei can have significant impact on the infant microbiome [20], but these changes have not yet been linked to health out- comes. Diet clearly shapes the microbiome [21] and, therefore, it may be that probiotic strategies must also be accompanied by dietary changes. Finally, emerging evidence for the potent regulatory activity of other bacterial strains such as Clostridia [22, 23] indicates the need for more testing of novel probiotics.

\section{References}

1 Guarner F, Schaafsma GJ: Probiotics. Int J Food Microbiol 1998;39:237-238.

-2 Madsen KL, Doyle JS, Jewell LD, Tavernini MM, Fedorak RN: Lactobacillus species prevents colitis in interleukin 10 gene-deficient mice. Gastroenterology 1999;116:1107-1114.

3 Madsen K, Cornish A, Soper P, McKaigney C, Jijon H, Yachimec C, Doyle J, Jewell L, De Simone C: Probiotic bacteria enhance murine and human intestinal epithelial barrier function. Gastroenterology 2001;121:580-591.

-4 Pessi T, Sutas Y, Hurme M, Isolauri E: Interleukin-10 generation in atopic children following oral Lactobacillus rhamnosus gg. Clin Exp Allergy 2000;30:1804-1808.

5 Blumberg R, Powrie F: Microbiota, disease, and back to health: a metastable journey. Sci Transl Med 2012;4:137rv137.

6 Parker DS: Manipulation of the functional activity of the gut by dietary and other means (antibiotics/probiotics) in ruminants. J Nutr 1990;120:639-648.

7 Strachan DP: Hay fever, hygiene, and household size. BMJ 1989;299:1259-1260.

$\checkmark$ Coates ME, O’Donoghue PN: Milk allergy in infant germ-free rabbits. Nature 1967;213: 307-308.

-9 Noval Rivas M, Burton OT, Wise P, Zhang YQ, Hobson SA, Garcia Lloret M, Chehoud C, Kuczynski J, Desantis T, Warrington J, Hyde ER, Petrosino JF, Gerber GK, Bry L, Oettgen HC, Mazmanian SK, Chatila TA: A microbiota signature associated with experimental food allergy promotes allergic sensitization and anaphylaxis. J Allergy Clin Immunol 2013;131:201-212.

10 Sepp E, Julge K, Mikelsaar M, Bjorksten B: Intestinal microbiota and immunoglobulin $\mathrm{E}$ responses in 5-year-old Estonian children. Clin Exp Allergy 2005;35:1141-1146.
-11 Adlerberth I, Strachan DP, Matricardi PM, Ahrne S, Orfei L, Aberg N, Perkin MR, Tripodi S, Hesselmar B, Saalman R, Coates AR, Bonanno CL, Panetta V, Wold AE: Gut microbiota and development of atopic eczema in 3 European birth cohorts. J Allergy Clin Immunol 2007;120:343-350.

12 Abrahamsson TR, Jakobsson HE, Andersson AF, Bjorksten B, Engstrand L, Jenmalm MC: Low diversity of the gut microbiota in infants with atopic eczema. J Allergy Clin Immunol 2012;129:434-440.

13 Wang M, Karlsson C, Olsson C, Adlerberth I, Wold AE, Strachan DP, Martricardi PM, Aberg N, Perkin MR, Tripodi S, Coates AR, Hesselmar B, Saalman R, Molin G, Ahrne S: Reduced diversity in the early fecal microbiota of infants with atopic eczema. J Allergy Clin Immunol 2008;121:129-134.

14 Garn H, Neves JF, Blumberg RS, Renz H: Effect of barrier microbes on organ-based in flammation. J Allergy Clin Immunol 2013; 131:1465-1478.

15 Faith JJ, Guruge JL, Charbonneau M, Subramanian S, Seedorf H, Goodman AL, Clemente JC, Knight R, Heath AC, Leibel RL, Rosenbaum M, Gordon JI: The long-term stability of the human gut microbiota. Science 2013;341:1237439.

16 Loo EX, Llanora GV, Lu Q, Aw MM, Lee BW, Shek LP: Supplementation with probiotics in the first 6 months of life did not protect against eczema and allergy in at-risk Asian infants: a 5-year follow-up. Int Arch Allergy Immunol 2013;163:25-28.

17 Soh SE, Aw M, Gerez I, Chong YS, Rauff M, Ng YP, Wong HB, Pai N, Lee BW, Shek LP: Probiotic supplementation in the first 6 months of life in at-risk Asian infants - effects on eczema and atopic sensitization at the age of 1 year. Clin Exp Allergy 2009;39:571-578.
18 Elazab N, Mendy A, Gasana J, Vieira ER, Quizon A, Forno E: Probiotic administration in early life, atopy, and asthma: a meta-analysis of clinical trials. Pediatrics 2013;132:e666e676.

19 Fiocchi A, Burks W, Bahna SL, Bielory L, Boyle RJ, Cocco R, Dreborg S, Goodman R, Kuitunen M, Haahtela T, Heine RG, Lack G, Osborn DA, Sampson H, Tannock GW, Lee BW: Clinical use of probiotics in pediatric allergy (CUPPA): a world allergy organization position paper. World Allergy Organ J 2012; 5:148-167.

20 Cox MJ, Huang YJ, Fujimura KE, Liu JT, McKean M, Boushey HA, Segal MR, Brodie EL, Cabana MD, Lynch SV: Lactobacillus casei abundance is associated with profound shifts in the infant gut microbiome. PLoS One 2010;5:e8745

21 Faith JJ, McNulty NP, Rey FE, Gordon JI: Predicting a human gut microbiota's response to diet in gnotobiotic mice. Science 2011;333: 101-104.

22 Atarashi K, Tanoue T, Shima T, Imaoka A, Kuwahara T, Momose Y, Cheng G, Yamasaki S, Saito T, Ohba Y, Taniguchi T, Takeda K, Hori S, Ivanov, II, Umesaki Y, Itoh K, Honda $\mathrm{K}$ : Induction of colonic regulatory $\mathrm{T}$ cells by indigenous Clostridium species. Science 2011; 331:337-341.

23 Atarashi K, Tanoue T, Oshima K, Suda W, Nagano Y, Nishikawa H, Fukuda S, Saito T, Narushima S, Hase K, Kim S, Fritz JV, Wilmes P, Ueha S, Matsushima K, Ohno H, Olle B, Sakaguchi S, Taniguchi T, Morita H, Hattori $\mathrm{M}$, Honda K: Treg induction by a rationally selected mixture of Clostridia strains from the human microbiota. Nature 2013;500:232236 